\title{
Simplification of gel point characterization of cellulose nano and microfiber suspensions
}

\author{
Jose Luis Sanchez-Salvador • M. Concepcion Monte • Carlos Negro • \\ Warren Batchelor • Gil Garnier • Angeles Blanco 10
}

Received: 15 March 2021 / Accepted: 10 June 2021/Published online: 17 June 2021

(C) The Author(s) 2021

\begin{abstract}
Nanocellulose is an emerging material that needs to be well characterized to control its performance during industrial applications. Gel point $\left(\varnothing_{\mathrm{g}}\right)$ is a convenient parameter commonly used to estimate the aspect ratio (AR) of cellulose nano/microfibers (CNFs/CMFs), providing critical information on the nanofiber network. However, its estimation requires many sedimentation experiments, tedious and time consuming. In this study, a simpler and faster technique is presented to estimate $\emptyset_{\mathrm{g}}$, based on one or two sedimentation experiments, reducing the
\end{abstract}

experiments by a factor of at least 2.5. Here, this new methodology is successfully validated by using the $\emptyset_{\mathrm{g}}$ of different $\mathrm{CNF} / \mathrm{CMF}$ hydrogels calculated with the traditional methodology, showing an error lower than $7 \%$. The error in the estimation of the AR is lower than $3 \%$ in all cases. Furthermore, the two mathematical models currently used to estimate $\emptyset_{\mathrm{g}}$, the smoothing spline and the quadratic fit, are compared and the mathematical assumptions improved.

J. L. Sanchez-Salvador - M. C. Monte .

C. Negro · A. Blanco $(\square)$

Chemical Engineering and Materials Department,

Universidad Complutense de Madrid, Avda. Complutense s/n, 28040 Madrid, Spain

e-mail: ablanco@ucm.es

W. Batchelor · G. Garnier

Chemical Engineering Department, BioPRIA, Monash

University, Clayton, VIC 3800, Australia 


\section{Graphical abstract}

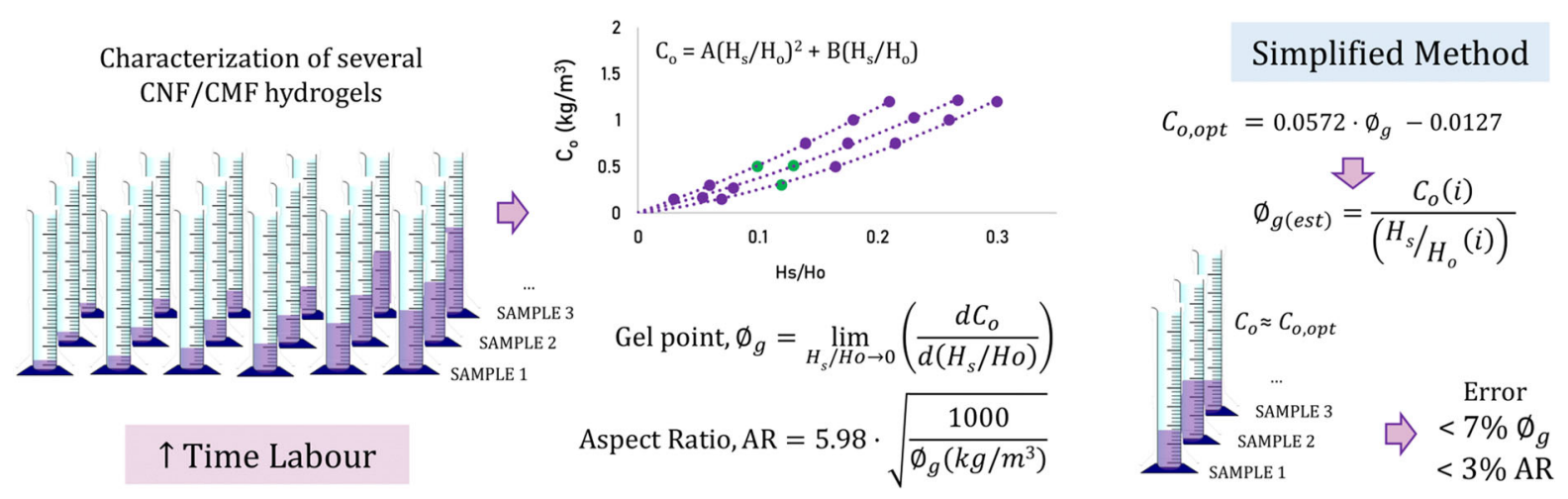

Keywords Aspect ratio - Cellulose nanofibers . Characterization $\cdot$ CSAPS smoothing spline $\cdot$ Gel point $\cdot$ Sedimentation

\section{Introduction}

Gel point $\left(\varnothing_{\mathrm{g}}\right)$ is defined as the volume concentration of a suspension at the boundary between the semidilute and dilute regions. This concentration is considered the lowest at which all flocs are interconnected, forming a self-supporting network (Martinez et al. 2001; Nasser and James 2006; Raj et al. 2016a; Zhang et al. 2012).

In the last few years, $\emptyset_{\mathrm{g}}$ has been used to estimate the aspect ratio (AR) of different cellulose materials such as cellulose fibers, fines, microfibers (CMFs) and nanofibers (CNFs) (Martinez et al. 2001; SanchezSalvador et al. 2020a; Varanasi et al. 2013) using two methods: the Effective Medium Theory (EMT) and the Crowding Number $(\mathrm{CN})$ theory (Celzard et al. 2009; Kerekes and Schell 1992).

Performing the $\varnothing_{\mathrm{g}}$ methodology requires at least 5 sedimentation experiments, each with a different initial fiber concentration $\left(\mathrm{C}_{\mathrm{o}}\right)$, which is time consuming and a drawback, especially in industry. Another difficulty is that sedimentation time increases from 2 to 10 days with the fibrillation degree of the fiber sample (Sanchez-Salvador et al. 2020a).

Two mathematical methods have been used to calculate gel point $\left(\varnothing_{\mathrm{g}}\right)$. In the first, the $\emptyset_{\mathrm{g}}$ was estimated from a quadratic fit using Eq. 1 according to Varanasi et al. (2013). In this case, $\varnothing_{\mathrm{g}}$ results from the derivative at the origin of the curve $\mathrm{C}_{\mathrm{o}}$ vs $\mathrm{H}_{\mathrm{s}} / \mathrm{H}_{\mathrm{o}}$ as indicated by Eq. 2 (Martinez et al. 2001).

$C_{o}=a\left(H_{s} / H_{o}\right)^{2}+b\left(H_{s} / H_{o}\right)$

$\emptyset_{g}=\lim _{H_{s} / H_{o} \rightarrow 0}\left(\frac{d C_{o}}{d\left(H_{s} / H_{o}\right)}\right)=b$

where $\mathrm{H}_{\mathrm{s}} / \mathrm{H}_{\mathrm{o}}$ is the sediment height $\left(\mathrm{H}_{\mathrm{s}}\right)$ normalized by the initial height $\left(\mathrm{H}_{\mathrm{o}}\right)$ as measured from fiber sedimentation directly in the graduated cylinder.

The second method was developed using the curve fitting tool (CSAPS) in MATLAB. $\varnothing_{\mathrm{g}}$ is obtained from the first derivative of each curve in the y-intercept (Raj et al. 2016b). In this case, a smoothing spline is fitted to the data with a smoothing parameter (p) oscillating in the interval $[0,1]$. For $p=0$, the equation solution is the least-squares straight line fit to the data, while, on the other extreme, for $p=1$, the solution is the variational or natural cubic spline interpolant. As $\mathrm{p}$ moves from 0 to 1 , the smoothing spline changes as the parameter approaches $p=1$ the equation is closer to the data than the straight line. Traditionally, a constant "p" parameter is used but it must be optimized for each of the different types of nanofibers as explained in Sect. 2.1.

Here, we compare the use of both mathematical methods and their optimization, since in many cases they are used regardless of its mathematical limitations. In addition, we present a simpler and faster technique with mathematical assumptions to characterize $\varnothing_{\mathrm{g}}$ and subsequently, the aspect ratio of nano/ microfiber suspensions. Besides, these simplifications may be applied to other kinds of suspensions. The 
main novelty of this method is the reduction in the number of sedimentation experiments to estimate $\emptyset_{\mathrm{g}}$ using only one sedimentation experiment, at an optimal $\mathrm{C}_{\mathrm{o}}\left(\mathrm{C}_{\mathrm{o}, \text { opt }}\right)$, based on a classical approximation of derivatives by a small finite difference close to zero. Thus, the number of experiments and time labour are reduced by at least a factor of 2.5. It is important to adequately select the optimal $\mathrm{C}_{\mathrm{o}}\left(\mathrm{C}_{\mathrm{o} \text {,opt }}\right)$, in order to obtain a sedimentation deposit neither too small to have a high experimental error nor too big to have a disproportionate increment. If this is not achieved, it will be necessary to do a second experiment with a new $\mathrm{C}_{\mathrm{o}}$ closer to $\mathrm{C}_{\mathrm{o} \text {,opt. }}$ The optimal concentration will depend on the type of fiber source, the pretreatment or the fibrillation degree.

\section{Theory}

Quadratic fit and smoothing spline function

After carrying out the sedimentation experiments with suspensions at different $\mathrm{CNF} / \mathrm{CMF}$ concentrations, $\mathrm{H}_{\mathrm{s}} /$ $\mathrm{H}_{\mathrm{o}}$ is measured in the graduated cylinders (See in Supplementary 1, Fig. S1), following the traditional methodology. Then, $\varnothing_{\mathrm{g}}$ is estimated using the quadratic fit or the CSAPS method.

When the quadratic fit is used, the conditions to obtain are based on Eqs. 1 and 2. In Eq. 1, the quadratic fit is forced to have an independent term equal to zero. This fact makes the parameter " $b$ " in Eq. 1 slightly lower than both the quadratic fit with the independent term and that calculated with the smoothing spline.

Using the CSAPS smoothing spline function requires to select the value of the " $p$ " parameter based on two criteria:

- The selection of the minimum smoothing parameter (p) to represent the data close to the origin accurately, with the y-intercept very close to zero.

- The first derivative of the function must provide a smooth and gradual increase with no local fluctuations.

The selection of the smoothing parameter (p) in CSAPS smoothing spline function varies for each sample, not being able to use the same " $p$ " value for all CNFs/CMFs. Figure 1 shows the differences between CSAPS smoothing spline functions using
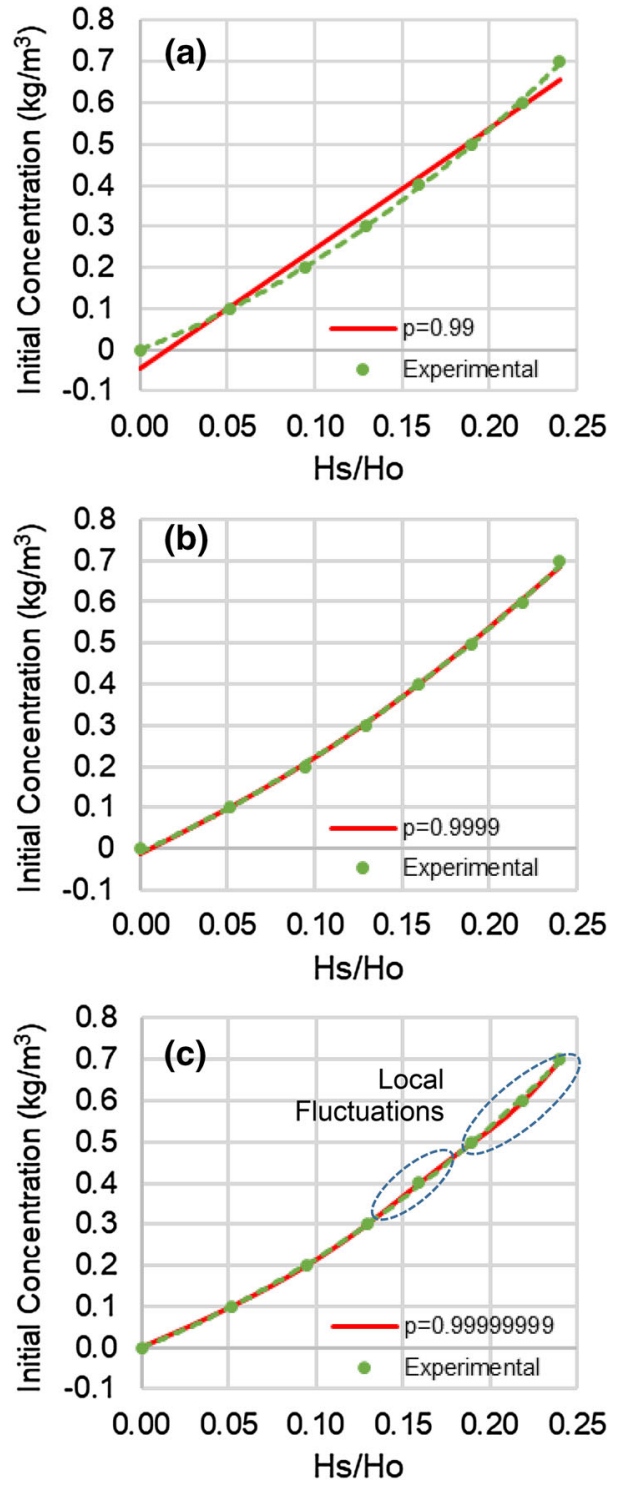

Fig. 1 Selection of the optimum $\mathrm{p}$ parameter of CSAPS smoothing spline function. Experimental data are fitted to the traditional quadratic fit; a " $p$ " value of $0.99 ; \mathbf{b}$ " $p$ " value of $0.9999 ; \mathbf{c}$ " $p$ " value of 0.99999999

different values of " $p$ " parameter for the results obtained in this study with the same CNF/CMF sample. In Fig. 1a, the "p" parameter is too low, and the curve shows a y-intercept far from zero and a linear trend. In Fig. 1c, the "p" parameter is too high, and the first derivative shows local fluctuations because the curve tries to connect the experimental values without obtaining a curve. However, the y-interception is almost zero. Therefore, the optimal parameter is an 
intermediate " $p$ " value" as shown in Fig. 1b. As consequence, the $\emptyset_{\mathrm{g}}$ calculated with different " $p$ " values that does not adequately represent the gel point curve may have variations even higher than $30 \%$. Further, the "p" parameter cannot be a fixed value for all samples as in some instances this value would show local fluctuations and an y-intercept very close to zero (similar to Fig. 1c); the same " $p$ " value in other samples would show a line far from the origin in the y-interception as in Fig. 1a. This is the reason why each sample should be selected with an appropriate p-value that adequately represents the $\emptyset_{\mathrm{g}}$ curve. For this, it will be necessary to find a mathematical model that defines a minimum p-value as shown in results, where the smoothing spline curve approaches the curve of the gel point, with a low error in the $y$-intercept and no local fluctuations of the curve.

\section{Simplifying assumptions}

The assumptions to simplify the $\emptyset_{\mathrm{g}}$ calculation are shown in Eq. 3. The derivative is replaced by a classical assumption, an increment between a determined concentration $\mathrm{C}_{\mathrm{o}}(\mathrm{i})$ and a theoretical concentration of zero, $\mathrm{C}_{\mathrm{o}}(0)$. Therefore, the derivative is approximated as the quotient between the difference of concentrations and the difference in the relation of heights. Both $\mathrm{C}_{\mathrm{o}}(0)$ and $\left(\mathrm{H}_{\mathrm{s}} / \mathrm{H}_{\mathrm{o}}(0)\right)$ are considered zero.

$$
\begin{aligned}
& \emptyset_{g}=\lim _{H_{s} / H_{o} \rightarrow 0}\left(\frac{d C_{o}}{d\left(H_{s} / H_{o}\right)}\right) \approx \emptyset_{g(e s t)} \\
& =\frac{C_{o}(i)-C_{o}(0)}{\left(H_{s / H_{o}}(i)\right)-\left(H_{s} / H_{o}(0)\right)}=\frac{C_{o}(i)}{(H s / H o(i))}
\end{aligned}
$$

$\emptyset_{\mathrm{g}}$ is the experimental gel point, $\varnothing_{\mathrm{g} \text { (est) }}$ is the estimated gel point for a specific $\mathrm{H}_{\mathrm{S}} / \mathrm{H}_{\mathrm{o}}(\mathrm{i})$ and $\mathrm{C}_{\mathrm{o}}(\mathrm{i})$ the selected initial concentration.

\section{Methods}

Determination of the optimal concentration

The selection of the best initial concentration $\left(\mathrm{C}_{\mathrm{o}, \mathrm{opt}}\right)$ requires a compromise solution. On the one hand, to obtain the minimum difference between $\emptyset_{\mathrm{g}(\text { est })}$ and the experimental $\varnothing_{\mathrm{g}}$, the closer the initial concentration to zero, the better. However, on the other hand, when the $\mathrm{H}_{\mathrm{s}} / \mathrm{H}_{\mathrm{o}}$ ratio is measured in graduated cylinders, the experimental error is significant at low $\mathrm{H}_{\mathrm{s}} / \mathrm{H}_{\mathrm{o}}$ (low initial concentration) and decreases at higher values.

Therefore, the determination of a relation between $\mathrm{C}_{\mathrm{o} \text {,opt }}$, to calculate $\emptyset_{\mathrm{g}(\text { est })}$, and $\varnothing_{\mathrm{g}}$ should be analyzed. For that, 25 gel point curves were studied from multiple CNFs/CMFs, most of them from published studies (Ang et al. 2020; Raj et al. 2016a; SanchezSalvador et al. 2020a) and others not published, and used to evaluate their relation and the best correlation as a function of $\varnothing_{\mathrm{g}}$. From them, the points of the curves $\mathrm{C}_{\mathrm{o}}$ vs $\mathrm{H}_{\mathrm{s}} / \mathrm{H}_{\mathrm{o}}$ were used to obtain $\mathrm{H}_{\mathrm{s}}$ for each point, the quadratic fit and also the smoothing spline fit calculated without local fluctuations nor y-intercept far from zero, as Fig. 1 indicates.

An example to determine the $\mathrm{C}_{\mathrm{o} \text {,opt }}$, from a gel point curve previously graphed, is shown in Fig. 2. The orange line shows $\emptyset_{\mathrm{g}(\mathrm{est})}$ of a sample curve for each $\mathrm{H}_{\mathrm{s}} / \mathrm{H}_{\mathrm{o}}$ (Eq. 4), assuming Eq. 1 to calculate $\mathrm{C}_{\mathrm{o}}$. On the other hand, $\emptyset_{\mathrm{g} \text { (est) }}$ obtained from experimental points are shown with the orange bullets, observing, as expected, a greater deviation at low $\mathrm{H}_{\mathrm{s}} / \mathrm{H}_{\mathrm{o}}$.

$$
\begin{aligned}
& \left.\emptyset_{g(e s t)}=\frac{C_{o}(i)}{(H s / H o}(i)\right)=\frac{a\left(H_{s} / H_{o}(i)\right)^{2}+b\left(H_{s} / H_{o}(i)\right)}{(H s / H o(i))} \\
& =a\left(H_{s} / H_{o}(i)\right)+b
\end{aligned}
$$

$\emptyset_{\mathrm{g}(\mathrm{est})}$ increases with $\mathrm{C}_{\mathrm{o}}$ and moves away from the $\emptyset_{\mathrm{g}}$ calculated by the quadratic fit (grey line, Fig. 2). As previously mentioned, the $\varnothing_{\mathrm{g}}$ quadratic fit is forced to

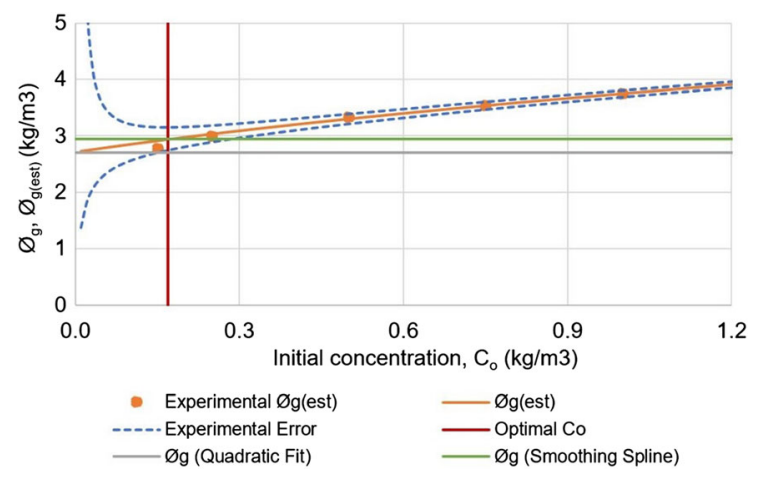

Fig. 2 Estimated gel point $\left(\emptyset_{\mathrm{g}(\mathrm{est})}\right)$ vs. Initial concentration $\left(C_{\mathrm{o}}\right)$. Obtention of the optimal initial concentration to simplify gel point method 
have an independent term equal to zero. Therefore, the " $b$ " parameter is slightly lower than the quadratic fit with independent term and the smoothing spline fit. However, the quadratic fit is useful to describe the $\emptyset_{\mathrm{g}}$ curve as in Eq. 4. On the other side, $\varnothing_{\mathrm{g}}$ calculated with the smoothing spline of MATLAB (green line), this line crosses the $\emptyset_{\mathrm{g}(\mathrm{est}) \text {. }}$ The exact interception depends on the "p" parameter selected that gives a different $\emptyset_{\mathrm{g}}$ value, as mentioned in Sect. 2.1.

To consider the experimental error due to the visualization of the $\mathrm{H}_{\mathrm{s}}$ using the common $250 \mathrm{~mL}$ graduated cylinders, we assumed an estimated error of $\mathrm{H}_{\mathrm{s}} \pm 1 \mathrm{~mL} . \mathrm{H}_{\mathrm{s}} / \mathrm{H}_{\mathrm{o}}$ and $\emptyset_{\mathrm{g}(\text { est })}$ were recalculated for each sample using Eq. 4, substituting $\mathrm{H}_{\mathrm{s}} / \mathrm{H}_{\mathrm{o}}$ by $\left(\left(\mathrm{H}_{\mathrm{s}} \pm 1\right) / \mathrm{H}_{\mathrm{o}}\right)$. The experimental error effect is shown in Fig. 2 by the dashed blue lines indicating the maximum lower and upper error.

Comparing $\varnothing_{\mathrm{g}(\mathrm{est})}$ with the possible experimental error, the upper blue line shows a minimum error value at the concentration indicated by the red line. Reading the initial concentration in the red line it is possible to obtain the $C_{o, o p t}$ and $\varnothing_{g(e s t)}$ with the minimum deviation. At this point, the difference between $\varnothing_{\mathrm{g}(\text { est })}$ and $\varnothing_{\mathrm{g}}$ calculated with the smoothing spline and a correct estimation of the " $p$ " parameter is minimum.

\section{Experimental validation}

To validate the simplifications of the new methodology, sedimentation experiments of 8 different types of CNFs and CMFs were carried out preparing suspensions at different initial concentrations. Three cellulose sources (cotton, eucalyptus and recycled paper) were tested to validate the simplifications with a wide range of morphologies and chemical compositions in order to try the method for all kinds of CNFs/CMFs. All samples were treated in a PANDA PLUS 2000 laboratory homogenizer (GEA Niro Soavi, Parma, Italy) at different passes and pre-treated with mechanical or chemical processes or not pre-treated. The characterization of the different samples, according to Sanchez-Salvador et al. (2020b), is summarized in Table 1.

The CNF/CMF suspensions at different $\mathrm{C}_{\mathrm{o}}$ were prepared using deionized water and stirred. $200 \mu \mathrm{L}$ of crystal violet $0.1 \mathrm{wt}$. \% was added to dye the fibers. $250 \mathrm{~mL}$ of each suspension were settled into graduated cylinders until the sediment reached a steady value to obtain the complete deposition of fibrils. $\mathrm{H}_{\mathrm{s}} /$ $\mathrm{H}_{\mathrm{o}}$ values were used to build the gel point curves.

\section{Results}

Comparison of the two mathematical methods to select the optimal initial concentration

$\mathrm{C}_{\mathrm{o} \text {,opt }}$ vs. $\emptyset_{\mathrm{g}}$ was calculated from 25 gel point curves from $\mathrm{CNFs} / \mathrm{CMFs}$ with different raw materials and treatments. The quadratic fit and the smoothing spline method were used to calculate $\emptyset_{\mathrm{g}}$ and to compare both methods in the estimation of $\mathrm{C}_{\mathrm{o} \text {,opt }}$. In a first approximation to compare both fits, the " $p$ " parameter of the smoothing spline function was selected to obtain a $y$-intercept less than 0.01. A MATLAB script to determine a suitable $\mathrm{p}$ value for each sample is shown in Supplementary 2, which inputs are the experimental points of the curve $\mathrm{C}_{\mathrm{o}}$ vs. $\mathrm{H}_{\mathrm{s}} / \mathrm{H}_{\mathrm{o}}$, and the outputs are the $\varnothing_{\mathrm{g}}$, the $\mathrm{p}$ value calculated and the value in the $\mathrm{y}$-interception. $\mathrm{C}_{\mathrm{o} \text {,opt }}$ was calculated as shown in Fig. 2; it does not depend on the $\varnothing_{\mathrm{g}}$ methodology, just to calculate the error regarding them. For further details, Supplementary 3 presents an example calculating $\mathrm{C}_{\mathrm{o} \text { opt }}$.

The relationship between $\mathrm{C}_{\mathrm{o} \text {,opt }}$ and $\emptyset_{\mathrm{g}}$ is observed in Fig. 3, which represents the errors between the $\emptyset_{\mathrm{g} \text {,est) }}$ calculated from Eq. 3 with $\mathrm{C}_{\mathrm{o} \text { opt }}$ as initial concentration and the experimental $\varnothing_{\mathrm{g}}$ for each methodology. Figure 3 shows that in both cases, the relationship between the $\mathrm{C}_{\mathrm{o} \text { opt }}$ and the experimental gel point is almost linear without significant differences in the residual sum of squares.

However, as Fig. 4 indicates, the error between the experimental $\varnothing_{\mathrm{g}}$ and $\varnothing_{\mathrm{g} \text {,(est) }}$ is different when using the smoothing spline or the quadratic fit methods. When the quadratic fit method is used, the average error for all samples shows that $\emptyset_{\mathrm{g} \text {,(est) }}$ is higher than $\emptyset_{\mathrm{g}}$ in $12.2 \% \pm 8.1$, whereas when using the smoothing spline fit, the average error is inferior with a value of $-7.8 \% \pm 6.4$. In both cases, the error is biased and depends on the value of $\varnothing_{\mathrm{g}}$.

As Fig. 4 indicates, the quadratic fit is not the best tool to estimate adequately the gel point due to the large deviations between $\emptyset_{\mathrm{g} \text {,(est) }}$ and $\varnothing_{\mathrm{g}}$. However, the smoothing spline option with a "p" value according to a fix y-interception is not adequate either because, for low gel point values, the errors are higher than for high 


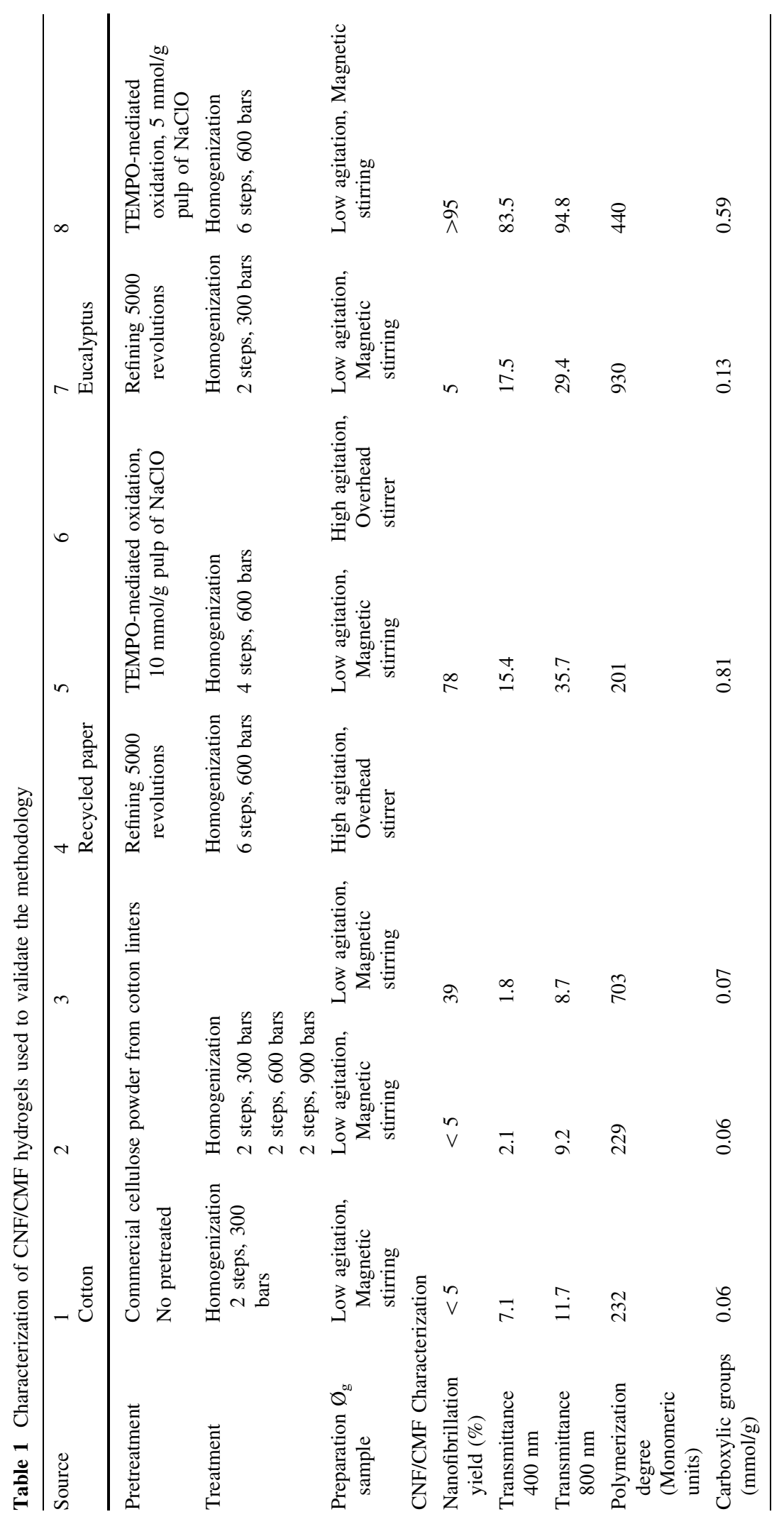




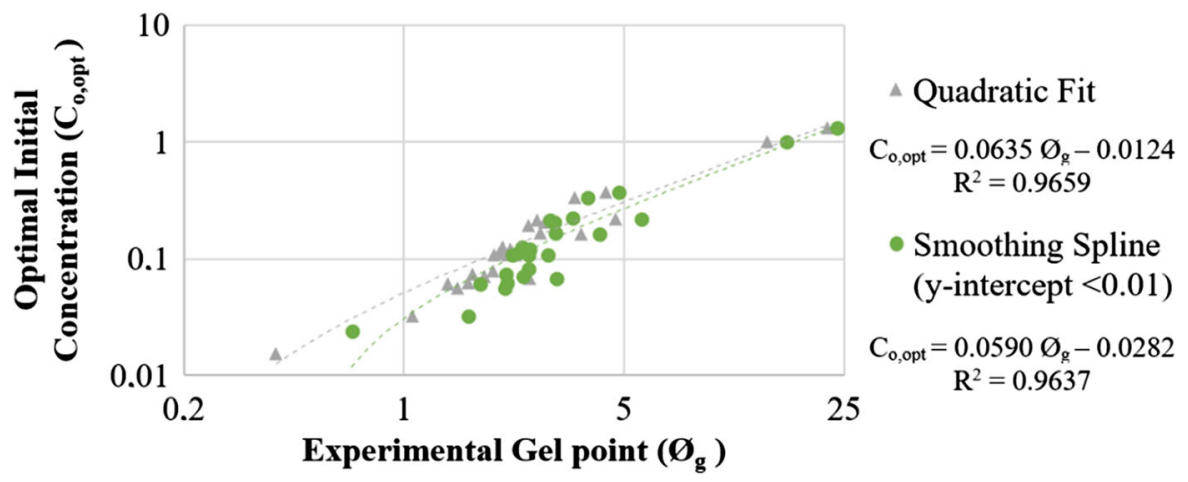

Fig. 3 Relation between the optimal initial concentration $\left(\mathrm{C}_{\mathrm{o}, \text { opt }}\right)$ and the experimental gel point $\left(\varnothing_{\mathrm{g}}\right)$

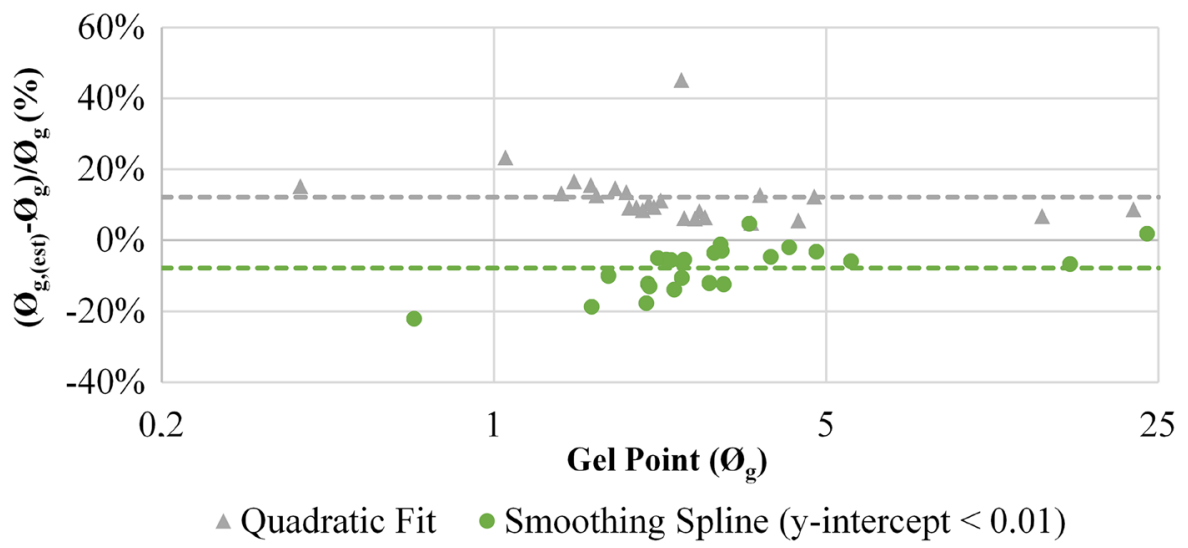

Fig. 4 Errors between the estimated gel point and the experimental gel point

gel point values. Therefore, an alternative is developed to calculate the gel point using the smoothing spline tool but optimizing the "p" parameter for each case.

Optimization of "p" parameter in smoothing spline as a function of gel point to select the optimal initial concentration

To avoid a biased error that depends on the value of $\emptyset_{\mathrm{g}}$, the y-interception error was set as a function of $\emptyset_{\mathrm{g}}$ using 7 conditions: (a) $<0.0005 \cdot \varnothing_{\mathrm{g}}$; (b) $<0.001 \cdot \varnothing_{\mathrm{g}}$; (c) $<0.0015 \cdot \varnothing_{\mathrm{g}} ; \quad$ (d) $<0.0017 . \varnothing_{\mathrm{g}} ; \quad$ (e) $<0.002 \cdot \varnothing_{\mathrm{g}}$; (f) $<0.0025 \cdot \varnothing_{\mathrm{g}}$; (g) $<0.005 \cdot \varnothing_{\mathrm{g}}$. A new MATLAB script (Supplementary 4) that replace the condition of a y-interception under 0.01 by the conditions a-g, in function of the $\varnothing_{\mathrm{g}}$. Figure 5 relates the $\mathrm{C}_{\mathrm{o} \text {,opt }}$ and the experimental gel point with different $y$-intercept as function of $\varnothing_{\mathrm{g}}$. The curves can be linearly adjusted in the same way as in Fig. 3 without significant differences. Figure 6 shows the error between the experimental and estimated $\varnothing_{\mathrm{g}}$ from these gel point estimations. The best results are obtained with a $\mathrm{y}$-intercept error under $0.0015 \cdot \varnothing_{\mathrm{g}}$ although the lower sum of squared residuals is obtained with a y-intercept error $<0.002 \cdot \emptyset_{\mathrm{g}}$. When the y-intercept error is under $0.001 \cdot \varnothing_{\mathrm{g}}$, some samples have local fluctuations in the MATLAB curve. A high y-intercept error (under $0.005 \varnothing_{\mathrm{g}}$ ) also shows a bad estimation with a high sum of squared residuals.

Validation of the assumptions to simplify gel point method

In order to validate the simplified gel point methodology, the results of full sedimentation experiments from 8 different $\mathrm{CNF} / \mathrm{CMF}$ samples (presented in Table 1) are considered (Fig. 7). 
From Fig. 7, the experimental gel point, using both the quadratic fit and the best smoothing spline fit (yintercept under $0.0015 \cdot \varnothing_{\mathrm{g}}$ ), were calculated (Table 2 ). In most of the cases a higher $\emptyset_{\mathrm{g}}$ using the smoothing spline fit is observed. From the $\emptyset_{\mathrm{g}}$ calculated by this last method, the $\mathrm{C}_{\mathrm{o} \text {,opt }}$ for a single experiment is calculated with Eq. 5 (obtained from Fig. 5). Calculation of $\mathrm{C}_{\mathrm{o} \text {,opt }}$ is not possible for the sample 1 as the $\emptyset_{\mathrm{g}}$ range in Eq. 5 is up to around 30 , since the nanocellulose is more in the form of nanocrystals instead of nanofibers. Therefore, $\varnothing_{\mathrm{g}}$ reaches a value of 317 which indicates a very low AR of around 10, usually corresponding to nanocrystals. For sample 2, the proximity of $\varnothing_{\mathrm{g}}$ with the range limit allows the calculation of $\mathrm{C}_{\mathrm{o} \text {,opt }}$. The differences between both mathematical methods are due to the forced fit without the independent term of the quadratic fit. Therefore, while the quadratic fit is a good tool to estimate a value in the curve $\mathrm{C}_{\mathrm{o}}$ vs. $\mathrm{H}_{\mathrm{s}} / \mathrm{H}_{\mathrm{o}}$, it is not the best method to obtain $\varnothing_{\mathrm{g}}$.

$C_{o, o p t}\left(\frac{\mathrm{kg}}{\mathrm{m}^{3}}\right)=0.0572 \cdot \emptyset_{g}\left(\frac{\mathrm{kg}}{\mathrm{m}^{3}}\right)-0.0127$
Table 3 shows the $\emptyset_{\mathrm{g} \text { (est) }}$ for several experimental points (red zone), calculated for the different types of CNFs/CMFs and $\mathrm{C}_{\mathrm{o}}$ from Fig. 7 and Eq. 3 In addition,

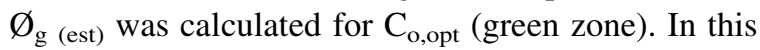
case, $\mathrm{H}_{\mathrm{s}} / \mathrm{H}_{\mathrm{o}}$ was obtained from the resolution of the quadratic fit of the data in Fig. 7 at $\mathrm{C}_{\mathrm{o} \text {,opt }}$ and using Eq. 3.

The results show that comparing $\varnothing_{\mathrm{g} \text { (est) }}$ at the $\mathrm{C}_{\mathrm{o} \text {,opt }}$ with the smoothing spline fit $\varnothing_{\mathrm{g}}$ the errors are under $7 \%$. $\varnothing_{\mathrm{g} \text { (est) }}$ in the experimental points at $\mathrm{C}_{\mathrm{o}}$ similar to the $C_{\mathrm{o} \text {,opt }}$ are also closer to the $\varnothing_{\mathrm{g}}$ obtained with the sedimentation curve and the smoothing spline fit. Concretely, bold marked results in Table 3 show the results with an error under $7 \%$ respect to the smoothing spline fit. This fact indicates a certain versatility in the selection of $\mathrm{C}_{\mathrm{o}}$ which would allow the use of a $\mathrm{C}_{\mathrm{o}}$ in the same order of magnitude of $\mathrm{C}_{\mathrm{o} \text { opt }}$ with a tolerable error without affecting the result to a greater extent. Some clarifications could be done in sample 4, whose $\mathrm{C}_{\mathrm{o} \text {,opt }}$ is $0.074 \mathrm{~kg} / \mathrm{m}^{3}$, half of minimum $\mathrm{C}_{\mathrm{o}}$ studied $\left(0.15 \mathrm{~kg} / \mathrm{m}^{3}\right)$, and would show an error slightly higher, around $12 \%$ at this concentration. On the other hand, sample 8 shows a low error during a wide

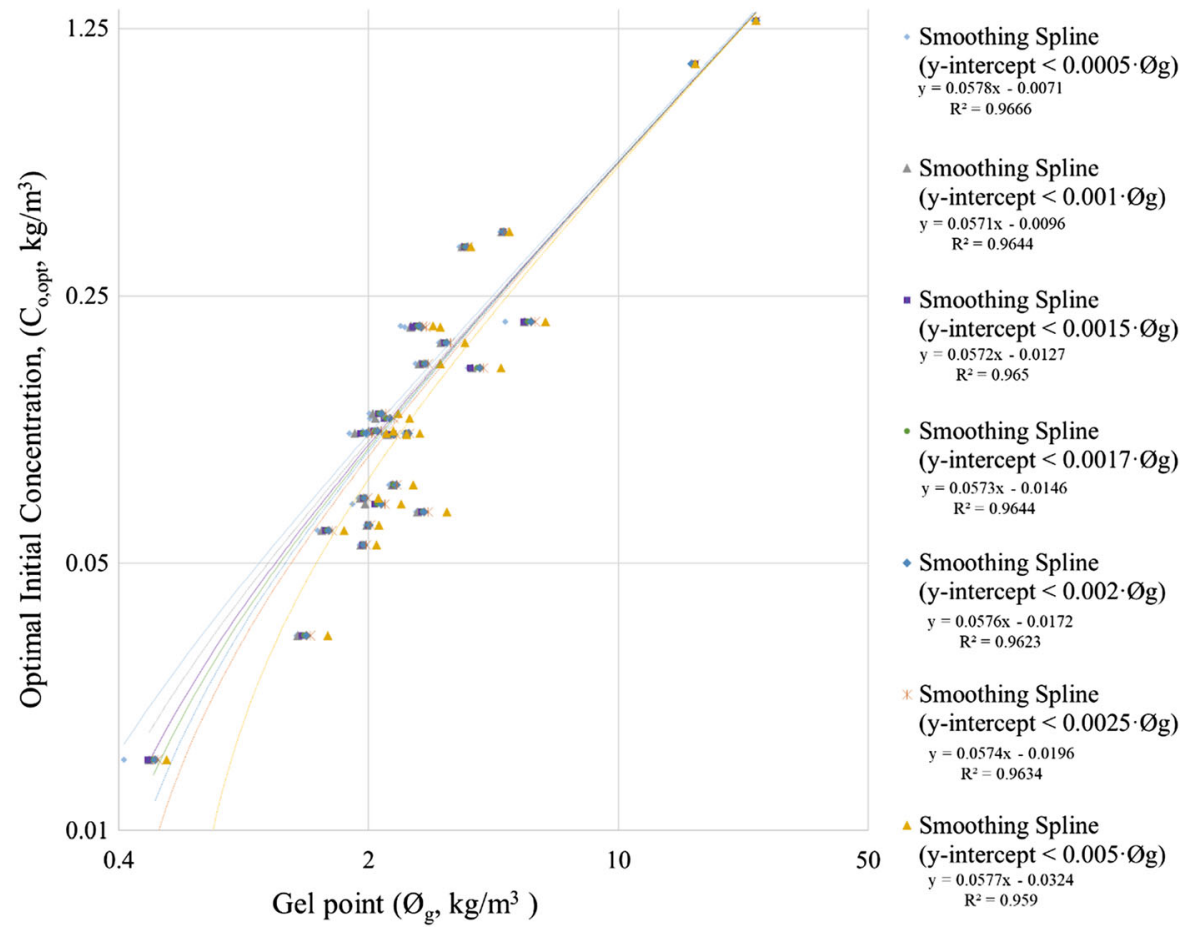

Fig. 5 Relation between the optimal initial concentration and the experimental gel point using the difference with the y-intercept as function of $\varnothing_{\mathrm{g}}$ 


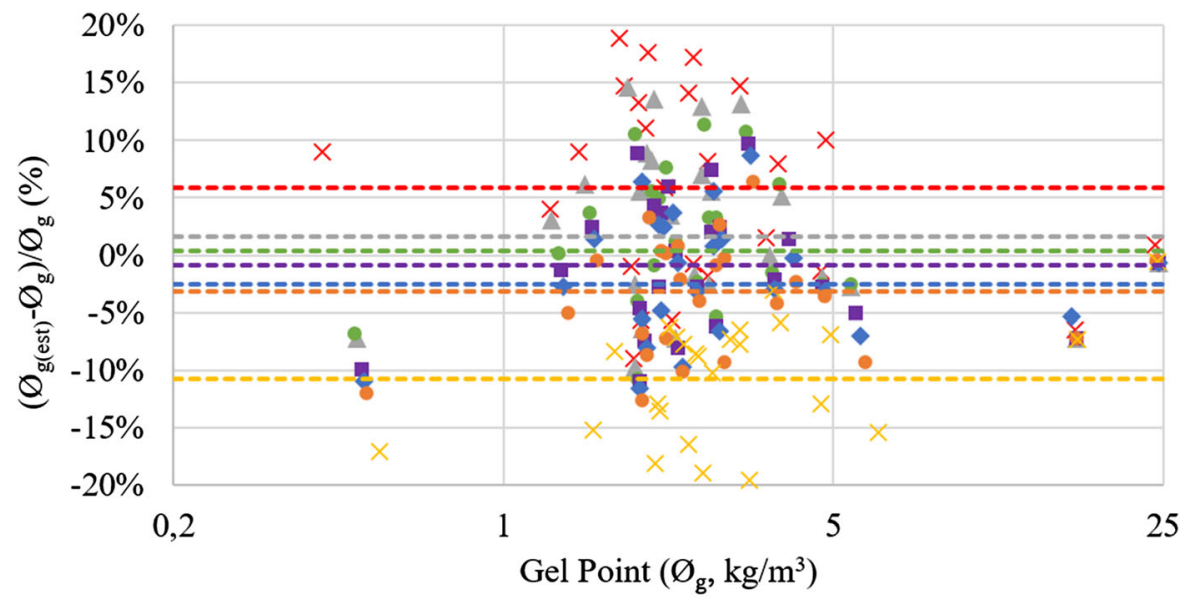

\begin{tabular}{|c|c|c|c|}
\hline & $\begin{array}{c}\left(\emptyset_{\mathrm{g},(\text { est })^{-}}\right. \\
\left.\emptyset_{\mathrm{g}}\right) / \varnothing_{\mathrm{g}} \\
\text { Average }(\%) \\
\end{array}$ & $\begin{array}{c}\text { Standard } \\
\text { desviation } \\
(\%)\end{array}$ & $\begin{array}{l}\text { Sum of } \\
\text { squared } \\
\text { residuals }\end{array}$ \\
\hline$x$ Smooth. Sp. $\left(y-i n t<0.0005 \cdot \varnothing_{g}\right)$ & 5.9 & 8.3 & 0.253 \\
\hline$\triangle$ Smooth. Sp. $\left(y\right.$-int $\left.<0.001 \cdot \emptyset_{\mathrm{g}}\right)$ & 1.6 & 7.9 & 0.139 \\
\hline - Smooth. Sp. $\left(y\right.$-int $\left.<0.0015 \cdot \varnothing_{\mathrm{g}}\right)$ & 0.4 & 6.2 & 0.093 \\
\hline - Smooth. Sp. $\left(y\right.$-int $\left.<0.0017 \cdot \emptyset_{\mathrm{g}}\right)$ & -0.9 & 5.8 & 0.082 \\
\hline Smooth. Sp. $\left(y\right.$-int $\left.<0.002 \cdot \emptyset_{\mathrm{g}}\right)$ & -2.5 & 5.9 & 0.080 \\
\hline - Smooth. Sp. $\left(y\right.$-int $\left.<0.0025 \cdot \emptyset_{\mathrm{g}}\right)$ & -3.2 & 5.7 & 0.095 \\
\hline$x$ Smooth. Sp. $\left(y\right.$-int $\left.<0.005 \cdot \varnothing_{\mathrm{g}}\right)$ & -10.7 & 5.2 & 0.339 \\
\hline
\end{tabular}

Fig. 6 Errors and statistics between the estimated gel point and the experimental gel point using the difference with the y-intercept as function of $\emptyset_{\mathrm{g}}$

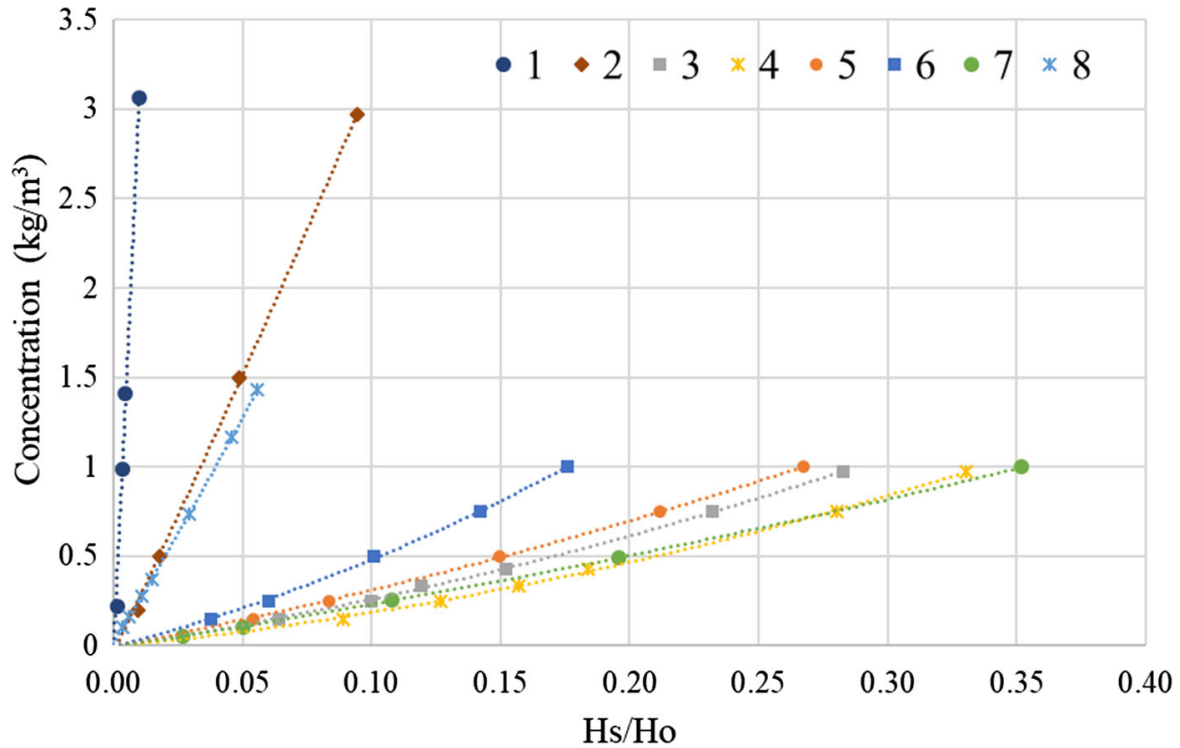

Fig. 7 Initial concentration of $\mathrm{CNFs} / \mathrm{CMFs}$ vs. $\mathrm{H}_{\mathrm{s}} / \mathrm{H}_{\mathrm{o}}$ 
Table 2 Gel point and optimal initial concentration for the $\mathrm{CNF} / \mathrm{CMF}$ samples using the quadratic fit and the smoothing spline function

\begin{tabular}{llll}
\hline Sample & \multicolumn{2}{l}{ Quadratic fit } & \multicolumn{2}{l}{ Smoothing spline $\left(<0.015 \cdot \emptyset_{\mathrm{g}}\right)$} \\
\cline { 3 - 4 } & $\left(\emptyset_{\mathrm{g}}\right)$ & $\left(\emptyset_{\mathrm{g}}\right)$ & $\left(\mathrm{C}_{\mathrm{o}, \text { opt }}\right)$ \\
\hline 1 & 281 & 317 & Out of range \\
2 & 28.4 & 31.2 & 1.77 \\
3 & 2.12 & 2.31 & 0.119 \\
4 & 1.39 & 1.52 & 0.074 \\
5 & 2.71 & 2.84 & 0.150 \\
6 & 3.63 & 4.00 & 0.216 \\
7 & 2.08 & 2.02 & 0.101 \\
8 & 25.0 & 25.5 & 1.44 \\
\hline
\end{tabular}

interval of $\mathrm{C}_{\mathrm{o}}$. This fact is associated to a more linear trend in the curve $\mathrm{C}_{\mathrm{o}}$ vs. $\mathrm{H}_{\mathrm{s}} / \mathrm{H}_{\mathrm{o}}$ in this sample, compared to a more pronounced curvature in the others.

Since $\varnothing_{\mathrm{g}}$ is used as a tool to estimate AR of $\mathrm{CNF} /$ CMF samples, AR was calculated in Table 3 according to the Eq. 6, employing the Crowding number theory $(\mathrm{CN})$ and assuming a cellulose density of $1500 \mathrm{~kg} / \mathrm{m}^{3}$ (Varanasi et al. 2013).

AspectRatio $=5.98 \cdot\left(\frac{\emptyset_{g}\left(\frac{k g}{m^{3}}\right)}{1000}\right)^{-0.5}$

As Eq. 6 indicates, AR is inversely proportional to the square root of $\emptyset_{\mathrm{g}}$. Therefore, the error between the $\mathrm{AR}$ using smoothing spline and $\mathrm{AR}$ with the $\mathrm{C}_{\mathrm{o} \text {,opt }}$ decrease with respect to the $\varnothing_{\mathrm{g}}$ error, reaching always values under $3 \%$.

Considerations to apply the simplify gel point methodology

The application of this simplification to measure $\varnothing_{\mathrm{g}}$ in CNFs and CMFs does not require the previous preparation of the $\emptyset_{\mathrm{g}}$ curve with more than 5 graduated cylinders. However, the selection of the

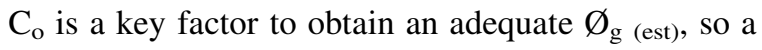
second additional experiment may be required in case of not obtaining a favourable result in the first one, using the Eq. 5 to recalculate a new $\mathrm{C}_{\mathrm{o}}$ according to the $\emptyset_{\mathrm{g} \text { (est) }}$ obtained in the first sample.
To select $\mathrm{C}_{\mathrm{o}}$ in the first experiment, the recommendation would be to obtain a sedimentation height around $4-12 \%$ of the total height, since a lower value would be difficult to measure with precision, and a higher $\mathrm{H}_{\mathrm{s}}$ would cause a great deviation in the substitution of the derivative for an increment (Eq. 3), moving away from the limit $\mathrm{H}_{\mathrm{s}} / \mathrm{H}_{\mathrm{o}}$ close to zero. The selection of $\mathrm{C}_{\mathrm{o}}$ depends on several factors as the raw material, the pretreatments or the intensity of the mechanical treatment.

A first approximation to select the value of $\mathrm{C}_{\mathrm{o}}$ for the first graduated cylinder could be carried our according to the pretreatment process:

- Refining: from $0.05-0.5 \mathrm{~kg} / \mathrm{m}^{3}$, using lower $\mathrm{C}_{\mathrm{o}}$ values as refining intensity increases.

- Enzymatic pretreatments: around $0.2-0.5 \mathrm{~kg} / \mathrm{m}^{3}$ due to the ratio length/diameter is very similar after pretreatment and mechanical treatments.

- Samples in a powder state: The decrease in length produces a lower AR and higher $\emptyset_{\mathrm{g}}$ as commercial cellulose powder from cotton linters, so the $\mathrm{C}_{\mathrm{o}}$ should be higher, $>1 \mathrm{~kg} / \mathrm{m}^{3}$.

- TEMPO-mediated oxidation: from 0.5 to $3 \mathrm{~kg} / \mathrm{m}^{3}$, using higher $\mathrm{C}_{\mathrm{o}}$ values as the oxidant dose increases.

In addition, the intensity of the mechanical treatment, as high-pressure homogenization, also produces a variation in the selection of $\mathrm{C}_{\mathrm{o}}$. In general terms, a high intensity in the mechanical treatment requires a low $\mathrm{C}_{\mathrm{o}}$ within the established ranges due to an increase of AR except in TEMPO-mediated oxidation, in which the intense mechanical treatment promotes not only the separation of the fibers, but also helps in the shortening of the fibers affected by the previous TEMPO-mediated pretreatment, increasing probably the $\varnothing_{\mathrm{g}}$ and, therefore, $\mathrm{C}_{\mathrm{o}}$.

After completing the first experiment $\emptyset_{\mathrm{g}(\mathrm{est})}$ is calculated and the $\mathrm{C}_{\mathrm{o} \text {,opt }}$ is obtained from Eq. 5. If the values of $\mathrm{C}_{\mathrm{o}}$ and $\mathrm{C}_{\mathrm{o} \text {,opt }}$ are too different, a second experiment should be carried out using a new $\mathrm{C}_{\mathrm{o}}$ close to $\mathrm{C}_{\text {o,opt }}$. The results of the $\mathrm{CNF} / \mathrm{CMF}$ samples studied in Table 3 show that at least when $\mathrm{C}_{\mathrm{o}}$ is in the interval $\left(0.5 \cdot \mathrm{C}_{\mathrm{o}, \mathrm{opt}}, 1.5 \cdot \mathrm{C}_{\mathrm{o}, \mathrm{opt}}\right)$, the $\emptyset_{\mathrm{g}(\mathrm{est})}$ error is under $7 \%$ in all cases. This approach cannot be used for micro or nanocrystals, since the AR must be higher than 30 . 
Table 3 Estimation of $\emptyset_{\mathrm{g}}$ and AR using different initial concentrations

\begin{tabular}{|c|c|c|c|c|c|c|c|c|c|c|}
\hline \multirow{2}{*}{$\begin{array}{l}\emptyset_{\mathrm{g}} \\
\text { sample }\end{array}$} & \multirow{2}{*}{$\begin{array}{l}\emptyset_{\mathrm{g}} \text { using smoothing } \\
\text { spline }\end{array}$} & \multicolumn{6}{|c|}{$\emptyset_{\mathrm{g} \text { (est) }}$ at different $\mathrm{C}_{\mathrm{o}}\left(\mathrm{kg} / \mathrm{m}^{3}\right)$-Experimental points } & \multicolumn{3}{|c|}{$\varnothing_{\mathrm{g} \text { (est) }}$ at the $\mathrm{C}_{\mathrm{o}, \mathrm{opt}}$ (according Eq. 5) } \\
\hline & & $\sim 0.15$ & $0.2-0.25$ & $0.5-0.75$ & $\sim 1$ & $\sim 1.5$ & $\bar{\sim} 3$ & $\mathrm{C}_{\mathrm{o}, \mathrm{opt}}$ & $\emptyset_{\mathrm{g}(\mathrm{est})}$ & $\begin{array}{l}\text { Error with smoothing } \\
\text { spline }\end{array}$ \\
\hline 1 & 317 & - & 157 & & 295 & 311 & 308 & \multicolumn{3}{|c|}{ Out of range } \\
\hline 2 & 31.2 & - & 21.6 & 28.1 & - & 30.7 & 31.5 & 1.77 & 30.3 & $2.8 \%$ \\
\hline 3 & 2.31 & 2.33 & 2.50 & 3.23 & 3.44 & - & - & 0.121 & 2.36 & $2.0 \%$ \\
\hline 4 & 1.52 & 1.69 & 1.97 & 2.68 & 2.94 & - & - & 0.074 & 1.60 & $5.5 \%$ \\
\hline 5 & 2.84 & 2.78 & 2.99 & 3.54 & 3.74 & - & - & 0.154 & 2.91 & $2.4 \%$ \\
\hline 6 & 4.00 & 3.95 & 4.17 & 5.28 & 5.68 & - & - & 0.217 & 4.22 & $5.5 \%$ \\
\hline 7 & 2.02 & 2.03 & 2.36 & 2.51 & 2.83 & - & - & 0.101 & 2.14 & $6.2 \%$ \\
\hline 8 & 25.5 & 26.7 & 25.5 & 25.0 & 25.4 & 25.7 & - & 1.45 & 25.6 & $0.6 \%$ \\
\hline \multirow{2}{*}{$\begin{array}{l}\text { AR } \\
\text { sample }\end{array}$} & \multirow{2}{*}{$\begin{array}{l}\text { AR using smoothing } \\
\text { spline }\end{array}$} & \multicolumn{6}{|c|}{ Estimation $\mathrm{AR}$ at different initial concentrations $\left(\mathrm{kg} / \mathrm{m}^{3}\right)$} & \multicolumn{3}{|c|}{ Aspect ratio using the $\mathrm{C}_{\mathrm{o}, \mathrm{opt}}$} \\
\hline & & $\sim 0.15$ & $0.2-0.25$ & $0.5-0.75$ & $\sim 1$ & $\sim 1.5$ & $\sim 3$ & $\mathrm{C}_{\mathrm{o}, \mathrm{opt}}$ & $\emptyset_{\mathrm{g} \text { (est) }}$ & $\begin{array}{l}\text { Error with smoothing } \\
\text { spline }\end{array}$ \\
\hline 1 & 10.6 & - & 15.1 & - & 11.0 & 10.7 & 10.8 & \multicolumn{3}{|c|}{ Out of range } \\
\hline 2 & 33.9 & - & 40.7 & 35.7 & & 34.1 & 33.7 & 1.77 & 34.3 & $1.4 \%$ \\
\hline 3 & 124 & 124 & 120 & 105 & 102 & - & - & 0.121 & 123 & $1.0 \%$ \\
\hline 4 & 153 & 145 & 135 & 116 & 110 & - & - & 0.074 & 149 & $2.6 \%$ \\
\hline 5 & 112 & 113 & 109 & 101 & 98 & - & - & 0.154 & 111 & $1.2 \%$ \\
\hline 6 & 95 & 95 & 93 & 82 & 79 & - & - & 0.217 & 92 & $2.6 \%$ \\
\hline 7 & 133 & 133 & 123 & 119 & 112 & - & - & 0.101 & 129 & $3.0 \%$ \\
\hline 8 & 37.4 & 36.6 & 37.4 & 37.8 & 37.5 & 37.3 & - & 1.45 & 37.3 & $0.3 \%$ \\
\hline
\end{tabular}

\section{Conclusion}

Nanocellulose is arguably the emerging nanomaterial of the last two decades. However, its full industrial deployment depends on the ability to conveniently characterize and control its quality during manufacturing. The gel point methodology is commonly used to calculate its aspect ratio (L/D) and could also be used to optimize its dispersion degree. However, sedimentation experiments are most tedious to perform which difficult its implementation in industrial environments and are certainly incompatible with industry environment and practice.

This study shows that the gel point can be estimated using one or two sedimentation experiments and selecting an optimal initial concentration $\left(\mathrm{C}_{\mathrm{o} \text { opt }}\right)$, based on the minimal experimental error and on a simplification of the gel point equations. The main simplification is that the derivative is replaced in a classical interpretation by an increment between a determined concentration and a theoretical concentration of zero. Therefore, the derivative is approximated as the quotient between $\mathrm{C}_{\mathrm{o}}$ and $\mathrm{H}_{\mathrm{s}} / \mathrm{H}_{\mathrm{o}}$.

The two usual methods to calculate $\varnothing_{\mathrm{g}}$, the smoothing spline and the quadratic fit, were compared. We conclude that the smoothing spline is generally the most reliable method, provided that the smooth spline fitting parameter is chosen correctly. Here, for the first time, an objective criterion for determining the appropriate smoothing spline parameter is presented.

The results obtained with the fitting procedures were validated with independent full studies of eight $\mathrm{CNF} / \mathrm{CMF}$ samples. It was possible to estimate the gel point from a single sedimentation experiment at the $\mathrm{C}_{\mathrm{o} \text {,opt }}$. The difference between the experimental $\varnothing_{\mathrm{g}}$ obtained by the $\varnothing_{\mathrm{g}}$ curve and the $\emptyset_{\mathrm{g}(\mathrm{est})}$ from the simplification was under $7 \%$ for all samples and under $3 \%$ in the case of the aspect ratio estimation. This was achieved with the smooth spline fitting parameter calculated using a MATLAB script in which y-interception in the curves $\mathrm{C}_{\mathrm{o}}$ vs. $\mathrm{H}_{\mathrm{s}} / \mathrm{H}_{\mathrm{o}}$ was $<0.0015 \emptyset_{\mathrm{g}}$. The main drawback of this simplification is the a priori 
selection of the $\mathrm{C}_{\mathrm{o} \text { opt }}$, so in some occasions if the selected $\mathrm{C}_{\mathrm{o}}$ is too far from the $\mathrm{C}_{\mathrm{o}, \text { opt }}$, the selected $\mathrm{C}_{\mathrm{o}}$ is not adequate and a new sedimentation experiment is required using the equation that relates $\varnothing_{\mathrm{g}}$ and $\mathrm{C}_{\mathrm{o} \text {,opt }}$.

This new method shows that the sedimentation experiments can be reduced by a factor of $2.5-5$ and is a promising tool to easily control nanocellulose quality and effectiveness during the different applications, compatible with industrial environments.

Acknowledgments The authors wish to thank the Economy and Competitiveness Ministry of Spain for the support of the project with reference CTQ2017-85654-C2-2-R, The Community of Madrid for the support to the Program Retoprosost2-S2018/EMT-4459 as well as the support of Universidad Complutense de Madrid and Banco de Santander for the grant of J.L. Sanchez-Salvador (CT17/17). Warren Batchelor and Gil Garnier wish to thank the Australian Research Council, Australian Paper, Carter Holt Harvey, Circa, Norske Skog and Visy for their support through the Industry Transformation Research Hub grant IH130100016.

\section{Declarations}

Conflict of interest The authors declare that they have no conflict of interest.

Open Access This article is licensed under a Creative Commons Attribution 4.0 International License, which permits use, sharing, adaptation, distribution and reproduction in any medium or format, as long as you give appropriate credit to the original author(s) and the source, provide a link to the Creative Commons licence, and indicate if changes were made. The images or other third party material in this article are included in the article's Creative Commons licence, unless indicated otherwise in a credit line to the material. If material is not included in the article's Creative Commons licence and your intended use is not permitted by statutory regulation or exceeds the permitted use, you will need to obtain permission directly from the copyright holder. To view a copy of this licence, visit http://creativecommons.org/licenses/by/4.0/.

\section{References}

Ang S, Haritos V, Batchelor W (2020) Cellulose nanofibers from recycled and virgin wood pulp: a comparative study of fiber development. Carbohyd Polym. https://doi.org/10. 1016/j.carbpol.2020.115900

Celzard A, Fierro V, Kerekes R (2009) Flocculation of cellulose fibres: new comparison of crowding factor with percolation and effective-medium theories. Cellulose 16(6):983-987. https://doi.org/10.1007/s10570-009-9314-0

Kerekes R, Schell C (1992) Regimes by a crowding factor. J Pulp Pap Sci 18(1):J32-38

Martinez DM, Buckley K, Jivan S, Lindstrom A, Thiruvengadaswamy R, Olson JA, Ruth TJ, Kerekes RJ (2001) Characterizing the mobility of papermaking fibres during sedimentation. In: The science of papermaking: transactions of the 12th fundamental research symposium, Oxford. The Pulp and Paper Fundamental Research Society, Bury, UK, pp 225-254

Nasser MS, James AE (2006) The effect of polyacrylamide charge density and molecular weight on the flocculation and sedimentation behaviour of kaolinite suspensions. Sep Purif Technol 52(2):241-252. https://doi.org/10.1016/j. seppur.2006.04.005

Raj P, Batchelor W, Blanco A, Fuente E, Negro C, Garnier G (2016a) Effect of polyelectrolyte morphology and adsorption on the mechanism of nanocellulose flocculation. J Colloid Interf Sci 481:158-167. https://doi.org/10. 1016/j.jcis.2016.07.048

Raj P, Mayahi A, Lahtinen P, Varanasi S, Garnier G, Martin D, Batchelor W (2016b) Gel point as a measure of cellulose nanofibre quality and feedstock development with mechanical energy. Cellulose 23(5):3051-3064. https:// doi.org/10.1007/s10570-016-1039-2

Sanchez-Salvador JL, Monte MC, Batchelor W, Garnier G, Negro C, Blanco A (2020a) Characterizing highly fibrillated nanocellulose by modifying the gel point methodology. Carbohyd Polym. https://doi.org/10.1016/j.carbpol. 2019.115340

Sanchez-Salvador JL, Balea A, Monte MC, Negro C, Miller M, Olson J, Blanco A (2020b) Comparison of Mechanical and chemical nanocellulose As Additives to Reinforce Recycled cardboard. Sci Rep 10(1):1-14. https://doi.org/10. 1038/s41598-020-60507-3

Varanasi S, He R, Batchelor W (2013) Estimation of cellulose nanofibre aspect ratio from measurements of fibre suspension gel point. Cellulose 20(4):1885-1896. https://doi. org/10.1007/s10570-013-9972-9

Zhang L, Batchelor W, Varanasi S, Tsuzuki T, Wang X (2012) Effect of cellulose nanofiber dimensions on sheet forming through filtration. Cellulose 19(2):561-574. https://doi. org/10.1007/s10570-011-9641-9

Publisher's Note Springer Nature remains neutral with regard to jurisdictional claims in published maps and institutional affiliations. 